\title{
Being stable and getting along with others: perceived ability expectations and employability among Finnish university students
}

\author{
Hannu Räty $^{1}$ (D) Inna Kozlinska ${ }^{2,3} \cdot$ Kati Kasanen $^{1} \cdot$ Päivi Siivonen ${ }^{1}$. \\ Katri Komulainen ${ }^{1}$ - Ulla Hytti ${ }^{4}$
}

Received: 31 January 2018 / Accepted: 3 June 2019 / Published online: 17 June 2019

(c) The Author(s) 2019

\begin{abstract}
The aim of this study was to examine what sort of ability expectations university students have about the requirements of working life, and how the perception of these expectations relate to students' perceptions of their own employability. The participants comprised a sample of students $(\mathrm{N}=1819)$ from two Finnish universities, representing diverse fields of study. They were asked to describe themselves according to a set of abilities and to then indicate those abilities that would be particularly important for them in the labour market. It was found that being stable and getting along with others were the most commonly considered generic capabilities for coping in working life. Furthermore, those university students who identified entrepreneurial skills and extroversion as predominant ability requirements were prone to have relatively pessimistic perceptions of their employability possibilities. Accordingly, the results of the study suggest that students' views of their expected abilities tend to shape their perceptions of their employment prospects, particularly with regard to entrepreneurial skills.
\end{abstract}

Keywords University students $\cdot$ Perceived abilities $\cdot$ Ability self $\cdot$ Expected abilities · Academic employability $\cdot$ Entrepreneurial skills

\section{Introduction}

\subsection{Perceptions of employability and abilities in an academic context}

Higher education is now seen as the reagent for economic growth and, thus, also a central policy concern of the nation states ability and skills formation strategies (Tomlinson 2012). The tightening link between universities and economic interests

Hannu Räty

hannu.raty@uef.fi

Extended author information available on the last page of the article 
shows up in the prevailing discourse of higher education policy that includes a request for universities to advance their students' employability skills; as a result universities are expected to set new standards for educating "entrepreneurial graduates" in particular (Laalo et al. 2019). Additionally, a fluctuating unemployment rate among the academically educated population in many countries, including Finland, has caused concern. In all, current changes have forced university students to consider their own employability. This consideration is typically conducted in reference to abilities by comparing a student's self-attributed abilities with the anticipated requirements of working life (Komulainen et al. 2012). Accordingly, the present study set out to contribute to the existing research literature by exploring the connection between students' perceptions of their abilities, or ability selves, and their perceptions of their employability.

Although university students' perspective on employability has been studied extensively, the ways in which students identify the ability requirements generated by labour markets and reproduced by universities in their entrepreneurship education, for example, has received little attention. For their part, students' expectations can be seen as reflecting normative social representations of abilities (cf. Moscovici 2000). Given that perceived expectations can accord with or be in conflict with students' perceptions of their current abilities and subsequent prospects, the present study set out to scrutinize not only what kinds of expectations university students regard as important ability requirements, but also how these expectations relate to the students' perceptions of their own employability.

As part of emerging trends of the labour market and even in education, entrepreneurship has been offered as one of the major means of employment (Boden and Nedeva 2010; Tomlinson 2012; in Finland, see Nurmi and Paasio 2007; Laalo et al. 2019). Employability is learning, having and developing general work-related abilities, so-called 'core' or 'enterprise' skills, such as creativity, problem-solving skills, innovativeness, flexibility, communication, social skills, teamwork, and the ability to take risks (McQuaid and Lindsay 2005; Bridgstock 2009). These skills indicate 'soft currencies', which are adaptable to a wide range of employment contexts (Payne 2000; Coetzee 2017) and are seen to help graduates become successful competitors in unstable labour markets.

For example, Potgieter (2012) described a collection of 'meta competences', which are viewed as vital psychological resources in an individual's career advancement, including self-esteem, sense of purpose and emotional literacy. In addition, extroversion (e.g. Kahnweiler 2013) and social skills such as networking, keenness to work in rapidly changing situations and the ability to lead teams are considered a central mind-set in today's working life (Sennett 2006). Subsequently, the concept of ability is also used as a generic notion in the present study, referring both to capabilities (e.g. innovativeness, emotional intelligence) and personality characteristics (e.g. honesty, talkativeness).

Obviously, there is a marked tension between the tenets of entrepreneurship and corresponding abilities on the one hand and the ethos of universities and related high-valued abilities such as theoreticality and criticality on the other (e.g. Komulainen et al. 2012). The topical discourse on employability is apt to challenge the value of traditional academic credentials - 'hard currencies' that appear in the form 
of academic qualifications - by placing the emphasis more on technical, social and personal skills that are not based on university degrees as such (Brown, Hesketh and Williams 2003; Prokou 2008; Tomlinson 2008).

Even if entrepreneurship is appreciated in Finland more than before, it apparently does not increase factual prospects for career and employment (for review of Finnish findings, see Tonttila 2010). For example, only a very small portion of Finnish parents considers it likely that their child would become an entrepreneur (Räty et al. 2016). According to a recent large-scale survey conducted in Finland, a great majority of university-educated young people would prefer to work as employees (69\%) rather than as entrepreneurs $(8 \%)$; what they generally want most of all in working life is stability and safety, rather than career advancement, increasing income or possibilities to function in international environments (Akava 2016).

The risk of unemployment has increased, while there is now a much larger and more diversified body of graduates in a crowded graduate labour market. For example, interview findings from the Finnish context suggest that some unemployed academics may even question whether a university education amounts to a personal merit that they can unequivocally be proud of (Siivonen et al. 2016). However, many feel that the accomplishment of an academic degree validates the fact that they possess overall and valuable theoretical abilities that can be applied in working life (Komulainen et al. 2015). A university degree and related theoretical abilities still represent a noteworthy component of their social identity (Räty 2015).

\subsection{Current and expected ability self}

There are at least two major ways to study employability of university graduates. First, academic employability can be defined as having a constellation of personal abilities that steer individuals towards proactive adaptability specific to work and careers (Coetzee 2017). Second, academic employability can also be approached through students' own perceptions of their current abilities and following subjective prospects in working life (e.g. Rothwell et al. 2008). The present study adopted this particular point of view, i.e. focusing on students' perceptions of their existing skills. These perceptions can be defined as the part of an individual's self-concept, 'ability self', which relates to the individual's evaluations of his/her abilities and other characteristics, understood as more or less internal and constant personal features which orientate an individual towards education, work and career (Komulainen et al. 2012).

Theoretically, this particular notion derives mainly from the social cultural research of the self (e.g. Markus and Kitayama 2010) and social-psychological research on social representations of intelligence (e.g. Mugny and Carugati 1989; Räty and Kasanen 2013). Accordingly, ability self is seen to develop through symbolically mediated interaction with others and a social environment. Selves are simultaneously representations of past behaviour and patterns for current and future behaviour and they are always situated and subsequently reflect their contexts in significant ways. 
Even though ability self is expressed in terms of personal qualities, as "ability talk", which makes it such a convincing individualizing mode of interpretation, the formation of an ability self is connected with an individual's institutional contexts and life-historical positions. In the present study, institutional context refers to the predominant social and cultural representations of intelligence maintained by educational system and labour market (cf. Räty et al.2012). Accordingly, the ability self is formed in the course of an individual's life-history, especially in the context of formal and informal evaluations. While participating in the differential routines of a school, students are predisposed to "learn their intelligence" by adopting the culturally prevalent criteria used to evaluate their potential (Rosenholtz and Simpson 1984), replicating the status hierarchy of abilities and the corresponding academic subjects (e.g. Räty et al. 2006).

Our central argument is that the notion of employability, like that of educability, is a social representation that is predominantly constructed in terms of abilities. To study educability and employability is to study important social-psychological sense-making phenomena through which the students come to understand their educational reality and forthcoming working life (e.g. Räty and Kasanen 2013).

We use the concept of 'current ability self' to refer to students' interpretations of their present abilities. In our previous (unpublished) study it was found that university students' ratings of their current abilities could be categorized into six domains: extroversion (e.g. talkative, skillful at building contacts), mental strength (e.g. coping with failures, strong self-confidence), innovativeness (e.g. innovative), ambitious-competitiveness (e.g. ambitious, competitive,) conventional employee skills (e.g. honest, cooperative) and academic abilities (e.g. theoretical, critical). Of these domains the conventional employee qualities were attributed most strongly to oneself, followed by academic abilities, ambitious-competitiveness and mental strength, and the least strongly attributed characteristics were innovativeness and extroversion. It appears, then, that entrepreneurial skills and extroversion contribute only to a moderate extent to students' present ability selves.

The concept of 'expected ability self' refers to students' anticipations of the abilities that working life is going to require of them. Students are invited, and even required, to connect themselves to normative social representations, introduced by educational organizations and the labour market. Even if the requirements do not necessarily lead an individual to reconstruct his/her present self, they connect him or her to socially constructed frameworks and act as vantage points that an individual is both aware of and must take into account (cf. Clémence 2001), whether she or he chooses to approach, avoid or confront, to quote the concepts put forward by Smith et al. (1958) in their characterization of attitudinal orientations.

Whereas an individual's ability self becomes dependent on the frame of comparison, s/he has several ability selves. According to Markus and Nurius (1986), 'possible selves' refers to the sort of person an individual could become (potential self), wants to become (ideal self), or is afraid of or does not want to become (undesired self). There can also be tensions among these different selves. Generally, self-discrepancies reflecting conflicts between an individual's actual and ideal selves are seen to have psychological consequences on an individuals' functioning and wellbeing. As Higgins (1987) maintains, people are torn between their own perceptions 
of themselves, the ideals that they and others wish for them and the responsibilities they feel (Rutherford 2015).

We can use the term expected ability self in cases in which perceived ability expectations have psychological implications; i.e. in the present case that expectations are prone to contribute to an individual's orientation towards working life, including the hopefulness they perceive in their own employability. The notion of employability, or self-perceived 'internal employability', is defined according to Rothwell et al. (2008) as including students' optimism and self-confidence and views of work-related relevance with regard to supposed abilities (also Rothwell et al. 2009).

\subsection{Research problems}

Our first major research question was to explore the content of university students' ability expectations: what sorts of abilities are acknowledged to indicate predominant requirements. We asked particularly to what extent 'entrepreneurial skills' are anticipated in comparison to other kinds of skills. Operationally, we requested a group of university students to evaluate themselves on a given set of attributes (the current ability self) and then to indicate which are the five attributes that they think will be especially required of them in working life (the expected ability self).

Our second major research question was to examine whether similarities exist among the expected abilities in terms of their psychological implications. Empirically, we asked whether the perceived ability expectation would be related to students' perceptions of their own employability. If that were to be the case, we could speak about an ability requirement that is already part of an individual's expected ability-self, given that we technically control the effects of students' current self, i.e. their self-attribution of the relevant ability. We assumed that a positive correlation would imply that in terms of a specific requirement, students are probably reflecting an approach orientation, whereas a negative correlation would suggest an 'undesired self', i.e. that a particular expectation is acknowledged but is perceived to pose some kind of threat to an individual's working life prospects, perhaps reflecting avoidance or even a confrontation orientation. We further assumed that a negative correlation would most probably pertain to entrepreneurial abilities once they tend to run counter to the virtues of the traditional ethos of university and subsequently to the academic identity to which students have socialized themselves.

\section{Method}

\subsection{Participants}

The survey was targeted at students from the multi-disciplinary Universities of Eastern Finland and Turku, which are located in different regional settings. However, in this survey our aim was not to compare the universities. As we tried to get a group that was as heterogeneous as possible in terms of students' fields 
of study, dissimilar study fields were targeted in these two universities. At the University of Eastern Finland, the Faculty of Social Sciences and Business Studies and the Faculty of Science and Forestry were included and at the University of Turku, the Faculty of Medicine and the Faculty of Humanities were included. Based on the faculties' records, the students' major fields of study were determined, and the questionnaires were distributed to all students doing their MA degree, which usually takes approximately 5 years to complete. Foreign students, postgraduate students and those who did not give permission to use their names in surveys were excluded. The study was conducted by means of an e-survey. The students were requested to complete the questionnaire on a voluntary basis and anonymously. The questionnaire took around 10-15 min to complete. Two days after the first circulation, the students were sent the first reminder, and the second reminder was sent after 1 week.

This research obtained informed consent from the participants according to the ethical principles set by the Finnish Advisory Board on Research Integrity (2019) and by the Research Council of the University of Eastern Finland (2019). Informed consent included the principles of the autonomy of research subjects, avoiding harm and privacy and data protection.

The response rate was $24 \%$, which is low but still relatively satisfactory in comparison to similar types of e-surveys. Of those who responded, $67 \%$ were female and $33 \%$ male, i.e. the females were somewhat more active, as the corresponding shares in the initial student population were $58 \%$ and $42 \%$, respectively. Students of the University of Eastern Finland $(26 \%)$ were more active than those of the University of Turku (20\%). With regard to the faculties, the highest response rate was obtained from the fields of the Faculty of Social Sciences and Business Studies (27\%) and the lowest from the fields of the Faculty of Humanities (19\%).

The participants comprised a sample of students, totalling 1819, at the University of Eastern Finland $(n=1387)$ and the University of Turku $(n=421)$, and unidentified cases $(n=11)$. Participant age varied between 18 and 60 years (mean age 29.4, SD =9.3). The following 10 fields were represented: social sciences $(n=438)$, business studies $(n=289)$, law $(n=295)$, natural sciences (chemistry, physics and mathematics, $n=108)$, computing science $(n=82)$, forest sciences and biology $(n=164)$, medicine $(n=112)$, nursing science $(n=45)$, languages $(n=120)$, humanities $(n=139)$, and unspecified $(n=27)$.

On average, $40 \%$ of the participants estimated that they had already completed $75-100 \%$ of their degree, whereas $19 \%$ estimated that they had completed less than 24\%. Almost one third (31\%) reported having a previous university degree. With regard to working life experience, $70 \%$ of the participants reported having at least 1 year of experience, $13 \%$ had from 1 month to 11 months, and $9 \%$ had no work experience at all. 


\subsection{Questionnaire}

The questionnaire, titled "Working life and me", comprised the following measures.

\subsubsection{Attributes of ability-self}

The attributes were derived from two major sources. Firstly, a well-established selfconcept inventory used in Finnish vocational guidance was employed (Häyrynen 1968). The inventory includes both personality traits (e.g. extroverted) and intellectual aptitudes (e.g. theoretical) and has been used to explore relationships between the multidimensional self-concept and occupational interests among vocationally and academically educated young people. Secondly, we reviewed the pertinent research literature and related public and political discussions on the employability skills needed in present-day labour markets (e.g. Fejes 2010; Komulainen et al. 2012).

The participants were first asked to evaluate how well the listed attributes, totaling 34, described them at that moment (the current ability self), using a five-point rating scale, anchored by "describes me very well" (5) and "does not describe me at all" (1). Then they were requested to indicate "which five attributes they thought working life would particularly require of them" (the expected ability self). For the analyses in the present study, an illustrative set of attributes was selected from the following ability domains, established by a factor-analysis: extroversion, mental strength, innovativeness and ambitious-competitiveness, conventional employee skills, and academic abilities (see Table 1).

\subsubsection{Self-perceived employability}

We chose all six statements from the scale developed by Rothwell et al. (2008) to measure self-perceived internal employability. These statements were translated into Finnish and one additional statement was included- "I believe that I will get a job in my field when I graduate". The participants were asked to indicate their agreement with the statements using a five-point Likert-scale anchored by "totally agree" (5) and "totally disagree" (1). The reliability coefficient (Cronbach's alpha) of the constructed mean scale was .86 , which is in line with that obtained by Rothwell et al. (2008). Item-scale correlations varied between .59 and .73, with an average of .63.

\section{Results}

\subsection{Perceptions of current and expected abilities and their interrelations}

As our study is exploratory, it was considered clarifying to conduct the analyses in terms of specific abilities rather than to construct domain-bound sum variables. Besides, as shown in Table 1, there were variations within each ability domain regarding the anticipation of abilities. About one fifth of the participants 
identified conventional employee skills as the expected ones, and over $70 \%$ named cooperative skills as a required capability. Similarly, one fifth of the participants refereed to attributes of mental strength as expected abilities, and almost $60 \%$ mentioned good stress tolerance as a required capability. Regarding the entrepreneurial skills, innovativeness was identified by one fifth of the students as an expected ability, whereas competitiveness was only seldom referred to. Concerning academic abilities, being theoretical and critical were indicated as expected abilities by a few students.

As the intercorrelations suggest, the students were generally inclined to choose expected abilities that they also attributed to themselves (Table 1). However, the strengths of the correlations were rather low. Thus, the perceptions of the current and expected abilities were relatively independent of each other.

Table 1 Students' perceptions of their current and expected abilities (means and standard deviations) and their intercorrelations

\begin{tabular}{|c|c|c|c|c|}
\hline \multirow[t]{2}{*}{ Ability domain } & \multicolumn{2}{|c|}{ Current abilities $^{\mathrm{a}}$} & \multirow{2}{*}{$\begin{array}{l}\text { Expected } \\
\text { abilities }{ }^{\mathrm{b}} \\
\%\end{array}$} & \multirow{2}{*}{$\begin{array}{l}\text { Correlation between assessments } \\
\text { of current and expected abilities }\end{array}$} \\
\hline & $M$ & $S D$ & & \\
\hline \multicolumn{5}{|l|}{ Extroversion } \\
\hline Talkative & 3.04 & 1.03 & 3 & $-.06 *$ \\
\hline Skilled at building contacts & 2.90 & 1.17 & 31 & -.00 \\
\hline Likes public speaking & 3.35 & 1.00 & 14 & $.10 * *$ \\
\hline \multicolumn{5}{|l|}{ Mental strength } \\
\hline Strong self-concept & 3.30 & .98 & 20 & .03 \\
\hline Copes with the failures & 3.21 & .98 & 19 & $.07 * *$ \\
\hline Good tolerance for stress & 3.57 & .99 & 59 & $.05^{*}$ \\
\hline \multicolumn{5}{|l|}{ Entrepreneurial skills } \\
\hline Enterprising & 2.73 & 1.11 & 11 & $.26 * *$ \\
\hline Innovative & 3.21 & .88 & 22 & $.14 * *$ \\
\hline Competitive & 3.15 & 1.10 & 7 & -.00 \\
\hline Ambitious & 3.73 & .94 & 15 & $.11 * *$ \\
\hline \multicolumn{5}{|l|}{ Conventional employee skills } \\
\hline Emotional intelligence & 4.43 & .67 & 18 & $.18 * *$ \\
\hline Honest & 3.97 & .89 & 18 & $.08 * *$ \\
\hline Cooperative & 4.22 & .69 & 74 & $.10 * *$ \\
\hline \multicolumn{5}{|l|}{ Academic skills } \\
\hline Theoretical & 3.25 & .95 & 3 & $.13 * *$ \\
\hline Critical & 3.91 & .75 & 8 & $.08 * *$ \\
\hline
\end{tabular}

$* p<.05 * * \mathrm{p}<.01$

${ }^{a}$ Refers to assessments of the current ability-self

${ }^{\mathrm{b}}$ Share of those students who indicated an attribute that working life would particularly require of them 


\subsection{Connections between perceptions of expected abilities and employability}

Linear regression analysis for each ability, totalling 15, was conducted with a forced entry method: the score of self-perceived employment (optimism) was set as the dependent variable, and the ratings of each ability, both currently perceived ones and those identified as expected $(0=$ not identified, $1=$ identified $)$, were included as the independent variables. Additionally, gender, age and field of study were included as the independent variables to control for their effects. Age was categorized into three approximately equally sized groups (18-23, 24-30 and 31-59 years of age), and the field of study was transformed into 10 dummy variables $(0=$ applicable, $1=$ inapplicable).

As displayed in Table 2, the students' ability ratings of their current abilities tended to have significant independent positive effects on their perceptions of employability, with the exception of theoreticality, which showed a significant reverse association. As to the expected abilities, all skills pertaining to extroversion and entrepreneurial abilities had significant negative effects on the students' perceptions of their employability, whereas skills pertaining to the conventional employee abilities-being honest and having emotional intelligence-displayed significant positive effects.

We noted that the students of medicine were prone to perceive their employment possibilities more optimistically than the students of other fields, whereas the students of biology and forestry sciences and especially of languages and humanistic studies were relatively pessimistic in their perceptions. Overall, the males were more optimistic than the females.

\section{Discussion}

\subsection{Overview of main findings}

This study set out to explore, in the context of topical educational discourse of employability, university students' ability expectations and the ways in which the perception of these expectations associates with students' perceptions of their own employability.

The first research problem dealt with the students' anticipations of the abilities called for in their future professional field. There were two abilities that were indicated by the great majority of participants: cooperativeness, representing conventional employee skills, and tolerance to stress, representing mental strength. Accordingly, getting along with others and being stable are quite commonly considered capabilities for managing in working life-capabilities that may be seen as indicating a rather well-established set of generic abilities (Potgieter 2012). These findings are in line with survey results showing that young academically educated people include social competences, such as group work, among the most important abilities in their future working life (Akava 2016).

Of the ability requirements, extroversion and entrepreneurial skills were identified by about $10-20 \%$ of the participants. However, there were two important exceptions, 


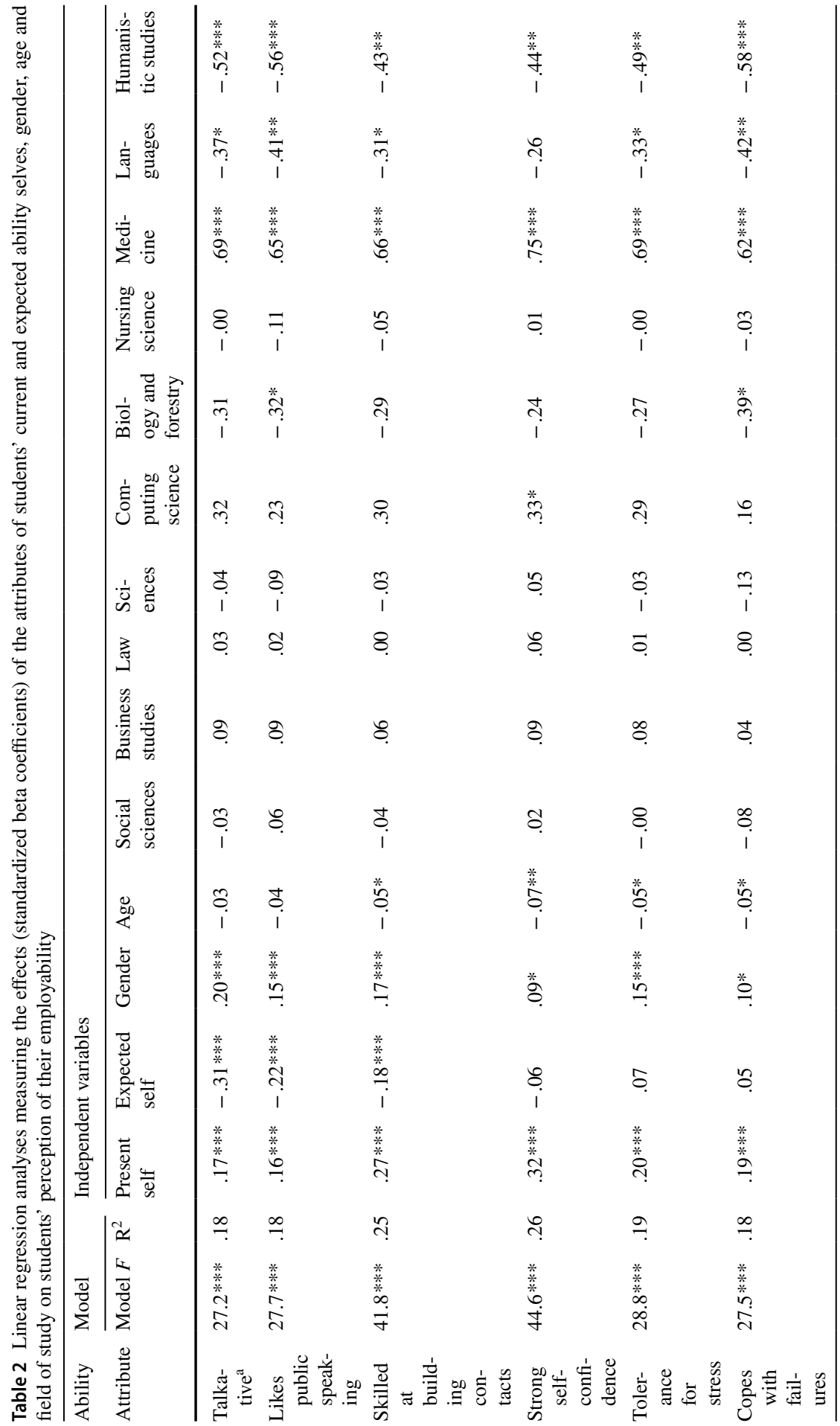




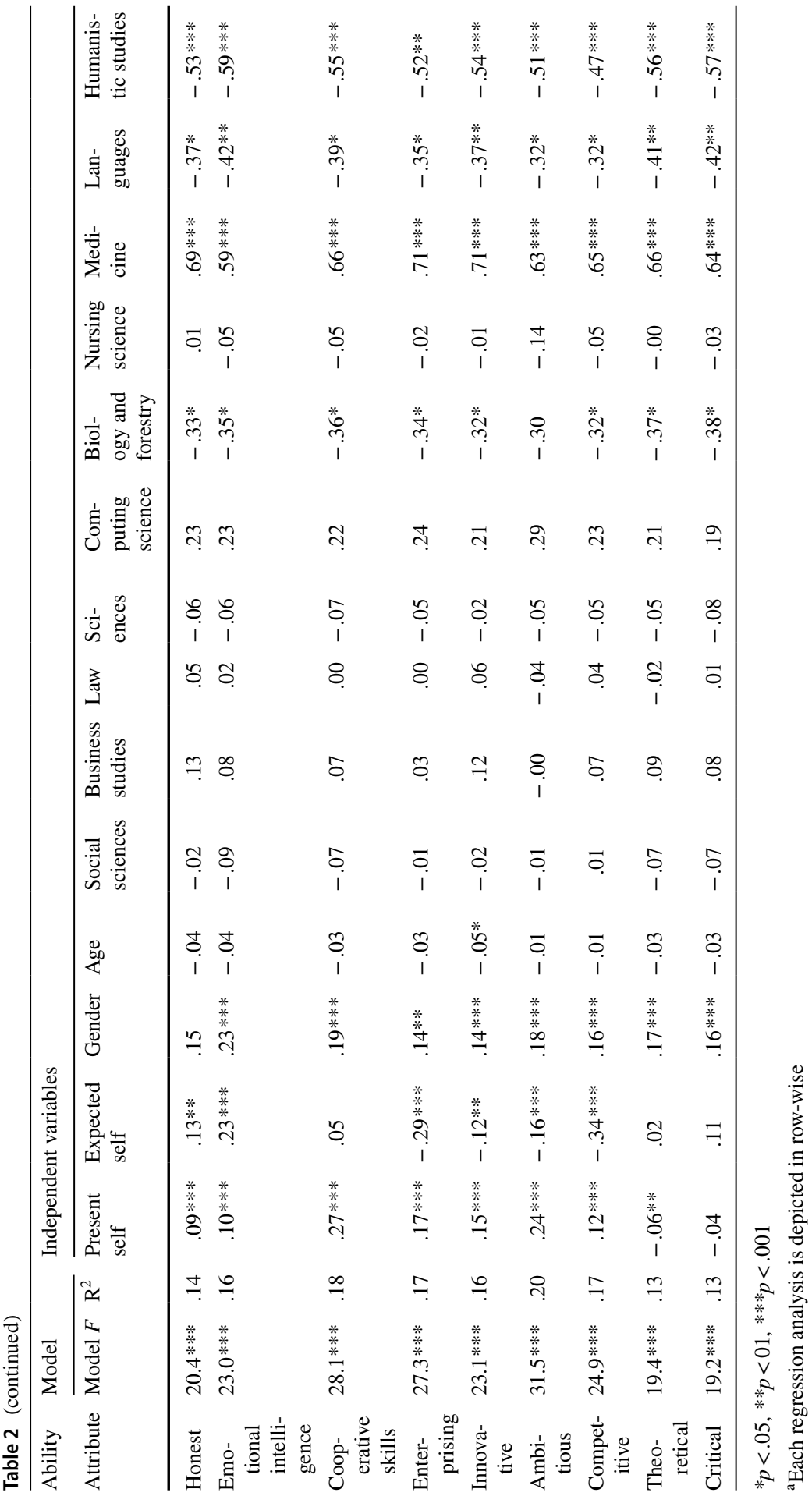


competition and talkativeness, which were noted by only a few students. We may ask whether competition was perceived as an irrelevant professional feature, or was it disliked and seen as something to be avoided? At least there is research evidence to show that a great majority of Finnish parents do not want competition in schools (Räty et al. 2012), suggesting that competition may exemplify an objectionable social value in the context of Nordic countries, where egalitarianism is underscored rather than mastery and achievement (cf. Schwartz 2006). Correspondingly, talkativeness is not positively included in the national self-stereotype (Raelo et al. 2009).

Being theoretical and critical were designated as academic skills in our survey. They were indicated as expected abilities by a few students, and theoreticality was the only capability in the current ability self that had a significant negative connection with self-perceived employability. Thus, it seems that at least these particular academic abilities are not regarded as 'hard currency' in working life (cf. Tomlinson 2012). Given that the students are still prone to attribute these abilities to themselves to a considerable extent, there is a potential tension between their current academic identity and their future professional identity. It is therefore no wonder that at least some unemployed academics may question the value of their university education (Siivonen et al. 2016).

This leads to our second research question concerning psychological implications pertaining to the identification of expected abilities. In line with our assumption, it was found that the students who felt that extroversion and entrepreneurial skills are the ones that working life is particularly going to require of them were inclined to see their employment prospects in a relatively pessimistic light. Although the students were also generally apt to attribute these abilities to their current ability self the connection between the perception of employability and the identification of expected abilities was independent of that inclination. Even if the identified working life abilities turned out to be psychologically significant, they seemed already to be included in the students' ability selves.

Importantly, the perceived expected abilities that were negatively connected to the subjective perception of employability turned out not to be a haphazard collection but were indeed restricted to the requirements that are manifest in the current discussion, i.e. those of entrepreneurial skills and extroversion (Sennett 2006). How can we understand these admittedly somewhat surprising findings? Conceivably, the identification of entrepreneurial skills and extroversion as predominant abilities holds an acknowledgment of their legitimacy or inevitability. The acknowledgment of these abilities may yet represent a form of potential self that one is afraid of or does not want to become, denoting what Markus and Nurius (1986) characterized as an 'undesirable self'. Accordingly, we are dealing with self-discrepancies reflecting tensions between an individual's present, anticipated and ideal selves (Higgins 1987).

As to entrepreneurial abilities and extroversion, our results suggest that there may be at least two somewhat overlapping ways in which students come to see their employment in a relatively pessimistic light: first, due to perceived insufficiency or lack of these skills and, second, due to the acknowledgment of the unwelcome and frightening importance of these skills- that may subsequently colour the working life horizon, even generally, in more or less adverse ways, including one's personal 
professional prospects. It would be interesting to explore whether this orientation relates to confrontation, entailing critical opinions about today's labour market (cf. Gratton 2011). After all, just like attitudes towards entrepreneurship education (Räty et al. 2016), interpretations of entrepreneurial abilities are not socially neutral but involve deep-seated social and even ideological differentiations (e.g. Räty et al. 2017).

The present finding that men appraised their employability in more optimistic terms than did women accords with research results according to which boys are already apt to indicate more confidence in their abilities and prospects than girls from primary school onwards (Marsh 1989).

In all, the results obtained suggest that the normative representation of abilities, reflecting the demands of working life and echoed by the universities, are related to students' ability selves and are also apt to generate potential psychological tensions. Whether these tensions for their part contribute eventually to the emergence of 'polemical' social representations is an interesting topic for future research (cf. Moscovici 2000). At least, there are already various forms of resistance among academics (Tapanila et al. 2018).

\subsection{Limitations and implications}

Our study has several limitations. First, although the size of our sample was rather large, the response rate was relatively low. In terms of representativeness, some fields of study were over-represented (e.g. various social sciences) and some fields were totally lacking (e.g. educational and technical sciences). With more representative samples, it would be advantageous to address differences among study fields with different academic identities and actual employment prospects.

Second, cross-national comparisons are needed in order to establish the possible cultural specificity of the present findings. For example, different national economies use different controls on the relationship between their higher education system and new skills strategies, and different national variations may profile how students recognise the connection between higher educational qualifications and their future returns (Tomlinson 2012).

Third, the way in which the expected abilities were measured was rather approximate. A more systematic evaluation of each ability would have yielded more reliable results and prevented possible haphazard identifications. Fourth, the list of abilities should be reviewed. For example, a group of digital and media literacy competences could well be included (Bridgstock 2009). The category of academic abilities could also be enlarged, although the delineation of what is a 'true' academic ability is bound to remain somewhat uncertain. For example, 'creativity' could be associated with academic research work or with 'innovativeness' in entrepreneurship.

Fifth, it would be interesting in future studies to look at whether the (factor) structure of the ratings of expected abilities would differ from that of current abilities. Finally, as we had no questions about students' academic performance or 
engagement, we could not scrutinize their relationship with students' ability selves and perceptions of employability.

Our findings offer some scope for policy implications. In terms of abilities, entrepreneurship appears to be conceived as a rather restricted category in the academic context - a category to which only a few specific individuals have access and, as the present study suggests, the acknowledgement of these enterprising abilities is linked with relatively adverse outlooks of one's own prospects. The expanding of entrepreneurship education at universities may unintentionally further accentuate the individualisation of one's responsibility, including blame, for his or her employability based on attributed personal characteristics or lack thereof (cf. Tomlinson 2010; Laalo et al. 2019). Social-psychologically, entrepreneurship is a restrictive category that may fail to keep many of its promises for employment. It is important, then, that universities could also critically evaluate projects related to entrepreneurship education.

To conclude, this study set out to contribute to existing knowledge by examining university students' ability expectations and the ways in which the perception of these expectations associates with students' perceived optimism regarding their own employability. The results obtained suggest that students' views of their expected abilities tend to shape their perceptions of their own employment prospects, particularly with regard to entrepreneurial skills.

Acknowledgements Open access funding provided by University of Eastern Finland (UEF) including Kuopio University Hospital. This work was supported by the Academy of Finland [Grant Number 295961].

\section{Compliance with ethical standards}

Conflict of interest The authors declare that they have no conflicts of interest.

Ethical approval The research followed the ethical principles set by the Finnish Advisory Board on Research Integrity (2019) and the Research Council of theUniversity of Eastern Finland (2019).

Open Access This article is distributed under the terms of the Creative Commons Attribution 4.0 International License (http://creativecommons.org/licenses/by/4.0/), which permits unrestricted use, distribution, and reproduction in any medium, provided you give appropriate credit to the original author(s) and the source, provide a link to the Creative Commons license, and indicate if changes were made.

\section{References}

Akava. (2016). Akava survey: Highly-educated young people want stability from their working life (Finnish). https://www.akavalainen.fi/akavalainen/arjessa/tyoelamassa/mita_korkeakoulutetut_nuore t_haluavat_tulevaisuuden_tyoelamalta.

Boden, R., \& Nedeva, M. (2010). Employing discourse: Universities and graduate 'employability'. Journal of Education Policy, 25, 37-54.

Bridgstock, R. (2009). The graduate attributes we've overlooked: enhancing graduate employability through career management skills. Higher Education Research and Development, 28, 31-44.

Brown, P., Hesketh, A., \& Williams, S. (2003). Employability in knowledge-driven society. Journal of Education and Work, 16, 107-126. 
Clémence, A. (2001). Social positioning and social representation. In K. Deaux \& G. Philogéne (Eds.), Representing the social (pp. 83-97). Oxford: Blackwell.

Coetzee, M. (2017). Graduates' psycho-social career preoccupations and employability capacities in the work context. In M. Tomlinson \& L. Holmes (Eds.), Graduate employability in context (pp. 295316). London: Palgrave Macmillan.

Fejes, A. (2010). Discourses on employability: Constituting the responsible citizen. Studies in Continuing Education, 32, 89-102.

Finnish Advisory Board on Research Integrity. (2019). Ethical review in human sciences. https://www. tenk.fi/en/ethical-review-in-human-sciences.

Gratton, I. (2011). The shift. The future work is already here. London: Collins.

Häyrynen, Y.-P. (1968). Ammatillisten intressien ja minäkuvan tutkimus [A study of vocational interests and self-concept]. Helsinki: Kulkulaitosten ja yleisten töiden ministeriön ammatinvalinnanohjaustoimisto.

Higgins, E. (1987). Self-discrepancy: A theory relating self and affect. Psychological Review, 94, 319-340.

Kahnweiler, J. (2013). Quite influence: The introvert's guide to making the difference. San Francisco: Berret-Koehler Publisher.

Komulainen, K., Räty, H., Korhonen, M., Siivonen, P., Kärkkäinen, R., \& Kasanen, K. (2012). Changing discourses of employability: From the meritocratic to the enterprise discourse of abilities? A review of the current and emerging research on abilities. In T. Tolonen, T. Palmu, S. Lappalainen, \& T. Kurki (Eds.), Cultural practices and transitions in education (pp. 92-94). London: The Tufnell Press.

Komulainen, K., Räty, H., Korhonen, M., Siivonen, P., Kasanen, K., Rautiainen, R., et al. (2015). 'Kun mikään ei riitä': Akateeminen kykyminä puntarissa ['While nothing is enough': Academic ability self in test]. In K. Brunila, J. Onnismaa, \& H. Pasanen (Eds.), Koko elämä töihin: Koulutus tietokykykapitalismissa [Whole life at work: Education in present-day capitalism] (pp. 145-172). Tampere: Vastapaino.

Laalo, H., Kinnari, H., \& Silvennoinen, H. (2019). Setting new standards for homo academicus: Entrepreneurial university graduates on the EU agenda. European Education, https://doi.org/10.1080/10564 934.2018.1489729.

Markus, H. R., \& Kitayama, S. (2010). Cultures and selves: A cycle of mutual constitution. Perspectives on Psychological Science, 5, 420-430.

Markus, P., \& Nurius, P. (1986). Possible selves. American Psychologist, 41, 954-969.

Marsh, H. (1989). Age and sex effects in multiple dimensional self-concept: Preadolescence to early adulthood. Journal of Educational Psychology, 81, 417-430.

McQuaid, R. W., \& Lindsay, C. (2005). The concept of employability. Urban Studies, 42, 197-219.

Moscovici, S. (2000). Social representations: Explorations in social psychology. London: Polity Press.

Mugny, G., \& Carugati, F. (1989). Social representations of intelligence. Cambridge: Cambridge University Press.

Nurmi, P., \& Paasio, K. (2007). Entrepreneurship in Finnish universities. Education + Training, 49, $56-65$.

Payne, J. (2000). The unbearable lightness of skill: The changing meaning of skill in UK policy discourses and some implications for education and training. Journal of Education Policy, 15, 353-369.

Potgieter, I. (2012). The relationship between the self-esteem and employability attributes of postgraduate business management students. SA Journal of Human Resource Management, 10, 1-15.

Prokou, E. (2008). The emphasis on employability and the changing role of the university in Europe. Higher Education in Europe, 33, 387-394.

Raelo, A., Allik, J., Verkasalo, M., Lönnqvist, J., Kwiatkowska, A., Kööts, L., et al. (2009). Mechanism of national character stereotype: How people in six neighboring countries of Russia describe themselves and the typical Russian. European Journal of Personality, 2, 229-249.

Räty, H. (2015). Notion of intelligence and social-educational identity. Educational Studies, 41, 272-275.

Räty, H., \& Kasanen, K. (2013). Parents' perceptions of their child's academic competencies construe their educational reality: Findings from a 9-year longitudinal study. Journal of Applied Social Psychology, 43, 1110-1119. https://doi.org/10.1111/jasp.12076.

Räty, H., Kasanen, K., \& Kärkkäinen, R. (2006). School subjects as social categorisations. Social Psychology of Education, 9(1), 5-25.

Räty, H., Komulainen, K., \& Hirva, L. (2012). Social representations of educability in Finland: 20 years of continuity and change. Social Psychology of Education, 15, 395-405. 
Räty, H., Korhonen, M., Kasanen, K., Rautiainen, R., Siivonen, P., \& Komulainen, K. (2016). Finnish parents' attitudes toward entrepreneurship education. Social Psychology of Education, 19, 385-401.

Räty, H., Mononen, N., \& Pykäläinen, E. (2017). Essentialism and social representations of intelligence. Social Psychology of Education, 20, 915-927.

Research Council of the University of Eastern Finland (2019). Good scientific practice. http://www.uef.fi/ en/research/research-council.

Rosenholtz, S., \& Simpson, C. (1984). The formation of ability conceptions: Developmental trend or social constructions? Review of Educational Research, 54, 31-63.

Rothwell, A., Herbert, I., \& Rothwell, F. (2008). Self-perceived employability: Construction and initial validation of scale for university students. Journal of Vocational Behavior, 73, 1-12.

Rothwell, A., Jewell, S., \& Hardie, M. (2009). Self-perceived employability: Investigating the responses of post-graduate students. Journal of Vocational Behavior, 75, 152-161.

Rutherford, T. (2015). Emotional well-being and discrepancies between child and parent educational expectations and aspirations in middle and high school. International Journal of Adolescence and Youth, 20, 69-85.

Schwartz, S. (2006). A theory of culture value orientations. Comparative Sociology, 5, 137-182.

Sennett, R. (2006). The culture of new capitalism. Yale: Yale University Press.

Siivonen, P., Komulainen, K., Räty, H., Korhonen, M., Kasanen, K., \& Rautiainen, R. (2016). Salvation of broken promise? Two adult graduates' social positioning in education and working life. Scandinavian Journal of Educational Research, 60, 110-125.

Smith, M. B., Bruner, J., \& White, R. (1958). Opinions and personality. New York: Wiley.

Tapanila, K., Siivonen, P., \& Filander, K. (2018). Academics' social positioning towards the restructured management system in Finnish universities. Studies in Higher Education, https://doi. org/10.1080/03075079.2018.1539957.

Tomlinson, M. (2008). 'The degree is not enough': Students' perceptions of the role of higher education credentials for graduate work and employability. British Journal of Sociology of Education, 29, 49-61.

Tomlinson, M. (2010). Investing in the self: Structure, agency and identity in graduates' employability. Education, Knowledge and Economy, 4, 73-88.

Tomlinson, M. (2012). Graduate employability: A review of conceptual and empirical themes. Higher Education Policy, 25, 407-431.

Tonttila, K. (2010). Yrittäjyyden arvottaminen akateemisten opiskelijoiden puheessa [Evaluation of entrepreneurship in the speech of academic students]. Doctoral dissertation, University of Helsinki https://core.ac.uk/download/pdf/14918801.pdf.

Publisher's Note Springer Nature remains neutral with regard to jurisdictional claims in published maps and institutional affiliations.

Hannu Räty, Ph.D is a professor at the University of Eastern Finland, Department of Education and Psychology. His research interests comprise social representations of educability and intelligence.

Inna Kozlinska, Ph.D is a postdoctoral researcher at the University of Groningen, Netherlands; and RISEBA University of Business, Arts and Technology, Latvia. Her research interests include entrepreneurial learning and evaluation of its outcomes.

Kati Kasanen Ph.D is a senior lecturer at the University of Eastern Finland, Department of Education and Psychology. Her research interests include social representations of educability and educational practices.

Päivi Siivonen, Ph.D is a docent in adult education and a senior researcher at the University of Eastern Finland, Department of Education and Psychology. Her research interests are higher education, ability conceptions and employability.

Katri Komulainen, Ph.D is a professor at the University of Eastern Finland, Department of Education and Psychology. Her research interests include social-cultural life course research as well as gender and education. 
Ulla Hytti, Ph.D is a research director at the University of Turku, Department of Management and Entrepreneurship. Her research focuses on entrepreneurial careers and identities, and entrepreneurship education.

\section{Affiliations}

\section{Hannu Räty ${ }^{1}\left[\begin{array}{l}{[0} \\ \text { Inna Kozlinska }\end{array}{ }^{2,3} \cdot\right.$ Kati Kasanen ${ }^{1} \cdot$ Päivi Siivonen ${ }^{1}$.} Katri Komulainen ${ }^{1} \cdot$ Ulla Hytti $^{4}$

Inna Kozlinska

i.kozlinska@rug.nl

Kati Kasanen

kati.kasanen@uef.fi

Päivi Siivonen

paivi.siivonen@uef.fi

Katri Komulainen

katri.komulainen@uef.fi

Ulla Hytti

ullhyt@utu.fi

1 University of Eastern Finland, P.O.Box 111, 80101 Joensuu, Finland

2 University of Groningen, Groningen, Netherlands

3 RISEBA University of Business, Arts and Technology, Riga, Latvia

4 University of Turku, Turku, Finland 